\title{
Short Review on the Conducting Polymer based Nanocomposites for Gas Sensing Applications
}

\author{
Syed Muhammad Imran ${ }^{1}$ and Manwar Hussain ${ }^{2 *}$ \\ ${ }^{1}$ Department of Chemical Engineering, COMSATS University Islamabad, Lahore Campus, Pakistan \\ ${ }^{2}$ Department of Department of Materials Science and Chemical Engineering, College of Engineering Sciences, Hanyang University, Republic of Korea
}

Submission: June 29, 2021; Published: July 15, 2021

*Corresponding author: Manwar Hussain, Department of Department of Materials Science and Chemical Engineering, College of Engineering Sciences, Hanyang University, Republic of Korea

\section{Abstract}

In the rapidly developing world a great concern regarding the protection and wellbeing of living beings and environment has led to the necessity for development of accurate monitoring processes through accurate and sensitive sensors. For these sensor applications conducting polymers nanocomposites have been widely used. In this article we will discuss about the conducting polymers, their mechanism of conduction, the sensing mechanism and different types of conducting polymers-based gas sensors. The prospects of conducting polymers-based gas sensor nanocomposites are also discussed in this article.

Keywords: Conducting polymers; nanocomposites; gas sensors; polymers; sensors

Abbreviations: CPs: Conducting Polymers; PANI: Polyaniline; PPy: Poly Pyrrole; PTs: Polythiophene; PEDOT: Poly 3,4-ethylenedioxythiophene

\section{Introduction}

\section{Conducting Polymers}

Recently the conducting polymers (CPs) have gained attention of researchers because of their tunable conducting properties, easy preparation, light weight and ease of process. Due to their higher conductivity values the CPs are referred as "synthetic metals". CPs are being used for variety of different application including energy storage devices, solar cells, capacitors, EMI shielding, pressure sensors and gas sensors. Although most of their potential is still unexplored. CPs are intrinsically conductive in nature due to their conjugated system coupled with atoms or conjugated structure with alternate single and double bonds. The mechanism of conductivity of CPs is based on the transmission of polarons and bipolarons and there are different factors that influence the conductivity of CPs, some of them are the conjugation length, chain length, polaron length, the charge transfer of adjacent molecules and type and concentration of doping [1-3]. Most common and important CPs include, polyaniline (PANI), poly pyrrole (PPy), polythiophene (PTs) and poly 3,4-ethylenedioxythiophene (PEDOT) [4,5].

\section{Sensing Principle of CPs and the factors that influence the performance of the conducting polymer-based gas sensors}

The mechanism of gas sensing in the case of CPs based sensors, involves the measuring of resistance variation with the interaction of gas and the sensing material. The interaction between gas and the sensing material changes the physical properties of the CPs sensors, such as resistance, absorbance and current [6]. Following are types of CPs based gas sensors reported in the literature based on their operational mechanisms
a. Chemiresistors
b. Semiconductor Sensors
c. Optical Gas Sensors
d. Piezoelectric Crystal Sensors
e. Amperometric Sensors

There are many factors that influence the performance of the gas sensing performance of CPs based sensors, including nature of the sensing material, design of the sensor, type and concentration of doping, chemical interaction of gas and CPs, physical interaction of gas and CPs etc. [7].

\section{Prospects of CPs based gas sensors}

Despite scientific advancement in the field of gas sensors there are some areas in which researchers are facing challenges some of them are the selectivity for a target gas, in depth understanding of response time and the mechanism of sensitivity. So, in future 
we will see that much more attention will be given for the development of flexible and wearable sensor devices developed through the advanced synthesis methods to improve dispersion and to get uniform properties of the nanocomposites [8,9].

\section{Conclusion}

In this article we have discussed the CPs structure, properties and conducting mechanism. We have also discussed the factors influencing the gas sensing of CPs based sensors, like design of the sensor, nature of the material etc. different types of gas sensors based on the sensing principles are also enlisted in the article. In future we will be seeing advanced synthesis and fabrication techniques in order to improve the repeatability, sensitivity and reliability of the CPs based gas sensors.

\section{References}

1. Gerard M, Chaubey A, Malhotra BD (2002) Application of conducting polymers to biosensors. Biosens Bioelectron 17(5): 345-359.

2. Sabu T, Nirav J, Vijay KT (2020) Functional Nanomaterials: Advances in Gas Sensing. Springer, Singapore, pp. 462.
3. Pal T, Banerjee S, Kar PM, Kamal KK (2020) Characteristics of Conducting Polymers. Handbook of Nanocomposite Supercapacitor Materials I: Characteristics. In: Kar KK, Springer International Publishing: 247-268.

4. Ansari MO, Ansari SA, Hwan CM, Pervez AS, Wahab AM, et al. (2018) Conducting Polymer Nanocomposites as Gas Sensors. Functional Polymers. Cham, Springer International Publishing, pp.1-30.

5. Wang Y, Liu A, Han Y, Li T (2020) Sensors based on conductive polymers and their composites: a review. Polym Int 69(1): 7-17.

6. Persaud KC (2005) Polymers for chemical sensing. Mater Today 8(4): $38-44$.

7. Fang Q, Chetwynd DG, Covington JA, Toh CS, Gardner JW (2002) Microgas-sensor with conducting polymers. Sensor Actuat B-Chem 84(1): 66-71.

8. Agrawal AV, Kumar N, Kumar M (2021) Strategy and Future Prospects to Develop Room-Temperature-Recoverable NO2 Gas Sensor Based on Two-Dimensional Molybdenum Disulfide. Nano-Micro Lett 13: 38.

9. Tai H, Si W, Zaihua D, Yadon J (2020) Evolution of breath analysis based on humidity and gas sensors: Potential and challenges. Sensor Actuat B-Chem 318: 128104.

\section{Your next submission with Juniper Publishers will reach you the below assets}

- Quality Editorial service

- Swift Peer Review

- Reprints availability

- E-prints Service

- Manuscript Podcast for convenient understanding

- Global attainment for your research

- Manuscript accessibility in different formats ( Pdf, E-pub, Full Text, Audio)

- Unceasing customer service

Track the below URL for one-step submission https://juniperpublishers.com/online-submission.php 